\title{
Cloning and Characterization of a Gene Encoding an Outer Membrane Protein Required for Siderophore-Mediated Uptake of $\mathrm{Fe}^{3+}$ in Pseudomonas putida WCS358
}

\author{
JOEY D. MARUGG,${ }^{1} \dagger$ LETTY A. DE WEGER, ${ }^{2}$ HENK B. NIELANDER,${ }^{1}$ MICKY OORTHUIZEN, ${ }^{1}$ \\ KEES RECOURT, ${ }^{1,2}$ BEN LUGTENBERG ${ }^{2}$ GERARD A. J. M. VAN DER HOFSTAD, ${ }^{1}$ AND PETER J. WEISBEEK ${ }^{1.3 *}$ \\ Department of Molecular Cell Biology ${ }^{1}$ and Institute of Molecular Biology, ${ }^{3}$ University of Utrecht, Padualaan 8 , \\ $3584 \mathrm{CH}$ Utrecht, and Department of Plant Molecular Biology, Leiden University, \\ Nonnensteeg 3, 2311 VJ Leiden, ${ }^{2}$ The Netherlands
}

Received 21 October 1988/Accepted 15 February 1989

\begin{abstract}
In iron-limited environments plant-growth-stimulating Pseudomonas putida WCS358 produces a yellowgreen fluorescent siderophore called pseudobactin 358. Ferric pseudobactin 358 is efficiently taken up by cells of WCS358 but not by cells of another rhizosphere-colonizing strain, Pseudomonas fluorescens WCS374. A gene bank containing partial Sau3A DNA fragments from WCS358 was constructed in a derivative of the broad-host-range cosmid pLAFR1. By mobilization of this gene bank to strain WCS374 a cosmid clone, pMR, which made WCS374 competent for the utilization of pseudobactin 358 was identified. By subcloning of the 29.4-kilobase (kb) insert of pMR the essential genetic information was localized on a $B g I I$ fragment of $5.3 \mathrm{~kb}$. Tn5 mutagenesis limited the responsible gene to a region of approximately $2.5 \mathrm{~kb}$ within this fragment. Since the gene encodes an outer membrane protein with a predicted molecular mass of 90,000 daltons, it probably functions as the receptor for ferric pseudobactin 358. The gene is flanked by pseudobactin 358 biosynthesis genes on both sides and is on a separate transcriptional unit. WCS374 cells carrying pMR derivatives with Tn5 insertions in the putative receptor gene did not produce the 90,000 -dalton protein anymore and were unable to take up $\mathrm{Fe}^{3+}$ via pseudobactin 358 . In WCS358 cells as well as in WCS374 cells the gene is expressed only under iron-limited conditions.
\end{abstract}

Like most other bacteria, fluorescent pseudomonads possess a high-affinity iron uptake system that is used for growth in environments in which the amount of available iron is low. The system involves the synthesis and excretion of powerful iron(III)-chelating molecules, i.e., siderophores (25), the subsequent binding of the iron-siderophore complex by specific membrane-associated proteins, and the uptake of the iron cation. The different fluorescent pseudomonads produce pyoverdin- or pseudobactin-type siderophores which have very similar structures. Their structures consist of a fluorescent chromophore, a dihydroxyquinoline moiety linked to an oligopeptide 5 to 10 amino acids long. They differ mainly in amino acid composition and sequence $(7,9$, $22,28)$.

Rhizosphere-colonizing Pseudomonas putida WCS358 (16) produces large quantities of the siderophore pseudobactin 358 when grown under iron-limited conditions (23). Pseudobactin 358 has a nine-amino-acid-long peptide which is attached to the fluorescent chromophore, and it contains three bidentate iron(III)-chelating groups (G. A. J. M. van der Hofstad et al., manuscript in preparation). Five gene clusters on the WCS358 genome that are involved in the pseudobactin 358-specific iron uptake system have been identified $(22,23)$.

Upon iron limitation new large outer membrane proteins with apparent molecular weights (MWs) between 70,000 and 100,000 are synthesized by fluorescent pseudomonads $(8,11$, $20,24)$. The presence of such iron-regulated proteins in the outer membrane suggests that they are involved in high-

\footnotetext{
* Corresponding author.

$\dagger$ Present address: Unilever Research Laboratory Vlaardingen, 3130 AC Vlaardingen, The Netherlands.
}

affinity siderophore-mediated $\mathrm{Fe}^{3+}$ uptake (26). Magazin et al. (20) cloned a gene encoding such an iron-inducible outer membrane protein and showed that it probably is the receptor for ferric pseudobactin of Pseudomonas sp. strain B10. In Pseudomonas syringae pv. syringae B301D an outer membrane polypeptide which has an MW of 74,000 and which probably serves as the receptor for ferric pyoverdin ${ }_{\mathrm{pss}}$ has been identified (8).

This considerable variation in apparent MWs for the pyoverdin-pseudobactin receptor proteins of fluorescent pseudomonads may well be a reflection of the diversity of the pyoverdin siderophores themselves, suggesting specificity in the recognition of the siderophore of a certain strain and its cognate receptor protein, a view that is supported by recent investigations $(5,18)$.

We have investigated the pseudobactin 358-specific siderophore receptor with $P$. putida WCS358 and Pseudomonas fluorescens WCS374 (16). The structure of pseudobactin 374, the siderophore of WCS374, has been determined and differs considerably from that of pseudobactin 358 (G. A. J. M. van der Hofstad, unpublished results). It was shown that WCS358 is able to utilize pseudobactin 358 as well as pseudobactin 374 , whereas WCS374 is only able to utilize its own siderophore (10). The inability of strain WCS374 to utilize pseudobactin 358 was used to isolate and analyze the gene for the receptor for ferric pseudobactin 358 .

\section{MATERIALS AND METHODS}

Bacterial strains and plasmids. Wild-type $P$. putida WCS358, its siderophore-defective $\left(\mathrm{Flu}^{-} \mathrm{Sid}^{+}\right)$mutant JM101, Escherichia coli strains, and plasmids used in this study have been described previously $(22,23)$. P. fluorescens WCS374 is a rhizosphere-colonizing isolate (16). 
KM26 is a siderophore-defective ( Flu $^{-}$Sid $^{-}$) Tn5 insertion mutant of strain WCS374 which was isolated in our laboratory (unpublished data). LWP58-55 is a mutant of strain WCS358 which produces only low-MW lipopolysaccharide (L. A. de Weger, unpublished data) and was used for the preparation of the antiserum. Phage lambda::Tn5 (cI857 b221) (4) was used for transposon mutagenesis of cosmid pMR. Cosmid pLAFR1B was constructed by insertion of the pUC-4K restriction site-mobilizing element, consisting of a kanamycin resistance gene with PstI, SalI, BamHI, and $E c o$ RI restriction sites at both ends (30), into the EcoRI site of pLAFR1 (15), followed by deletion of the kanamycin resistance gene from the construct by digestion with $B a m \mathrm{HI}$. The resulting cosmid, pLAFR1B, contains a unique Bam $\mathrm{HI}$ site flanked by two EcoRI sites.

Growth conditions. E. coli and Pseudomonas strains were grown as described previously (23). The concentrations of antibiotics (in micrograms per milliliter) were as follows: ampicillin, 100 (for $E$. coli) and 500 (for P. putida WCS358); kanamycin, 25; nalidixic acid, 25; and tetracycline, 25 (all from Boehringer Mannheim Biochemicals, Indianapolis, Ind.). Piperacillin (Sigma Chemical Co., St. Louis, Mo.) (25 $\mu \mathrm{g} / \mathrm{ml}$ ) was used for selection of the pKT240 subclones in strain WCS374.

DNA manipulations and conjugations. Plasmid DNA isolation, restriction endonuclease digestion, gel electrophoresis, cloning procedures, and other DNA techniques were performed as described previously $(21,22,23)$. Triparental filter matings were performed with the helper strain $E$. coli HB101(pRK2013) $(13,14,22)$. Complementation of siderophore-defective mutants was scored by screening transconjugants for fluorescence (23). The ability to grow on pseudobactin 358 was measured by screening transconjugants on $\mathrm{KB}$ agar plates containing $100 \mu \mathrm{M}$ pseudobactin 358 and $100 \mu \mathrm{g}$ of ethylene-diaminedi( $o$-hydroxyphenylacetic acid) (EDDA; Sigma) per ml unless otherwise stated.

Purification of siderophores. Siderophores were isolated from culture supernatants of 64 -h-old cultures in standard succinate medium as described by van der Hofstad et al. (29) and de Weger et al. (10). Contaminating proteins in the culture supernatant were precipitated with $100 \%$ ammonium sulfate. After extraction with phenol-chloroform (1:1 [wt/ vol]) pseudobactins were precipitated with diethyl ether. Finally, pseudobactin 358 was purified to homogeneity by DEAE-Sephadex chromatography (G. A. J. M. van der Hofstad et al., manuscript in preparation).

$\mathrm{Fe}^{3+}$ uptake measurements. $\mathrm{Fe}^{3+}$ uptake measurements were taken as described by de Weger et al. (10). Briefly, cells were incubated with 0.5 to $1.0 \mu \mathrm{M}^{55} \mathrm{Fe}^{3+}$-pseudobactin, and at regular time intervals $0.5-\mathrm{ml}$ samples were removed. Cells were separated from the medium by centrifugation through a layer of silicone oil. The radioactivity associated with the pellet was measured with the tritium channel of an LKB 1214 Rackbeta liquid scintillation counter with $34 \%$ efficiency. The results are representative of at least three separate experiments which yielded essentially the same results.

Construction of a gene bank. A partial Sau3A digest of genomic WCS358 DNA was fractionated as described previously (23). DNA fragments ranging from 15 to 35 kilobases (kb) were ligated in the BamHI site of pLAFR1B. The ligated DNA was packaged into lambda phage heads, followed by transduction of phage particles to $E$. coli HB101 as described previously $(17,23)$.

Tn5 mutagenesis. Tn5 mutagenesis of E. coli HB101 carrying cosmid pMR was carried out by the method of Shaw and Berg (27). Mutagenized cosmids were selected by isola-
TABLE 1. Siderophore specificity of $P$. putida WCS358 and $P$. fluorescens WCS374

\begin{tabular}{|c|c|c|c|c|c|c|}
\hline \multirow{3}{*}{ Strain } & \multicolumn{6}{|c|}{$\begin{array}{l}\text { Growth on KB agar in the presence of the indicated } \\
\text { concn }(\mu \mathrm{M}) \text { of pseudobactin: }\end{array}$} \\
\hline & \multicolumn{3}{|c|}{358} & \multicolumn{3}{|c|}{374} \\
\hline & 25 & 50 & 100 & 25 & 50 & 100 \\
\hline WCS358 & + & + & + & + & + & + \\
\hline WCS374 & + & - & - & + & + & + \\
\hline
\end{tabular}

"Both wild-type WCS358 and WCS374 were plated (about 200 cells per plate) on KB agar supplemented with different concentrations of pseudobactin 358 and pseudobactin 374 and were incubated at $30^{\circ} \mathrm{C}$. The plates were examined for growth after $18 \mathrm{~h}$. + . Growth: -, no growth.

tion of the cosmids, followed by transformation of HB101. Kanamycin- and tetracycline-resistant transformants were pooled and conjugated with KM26 cells.

Cell envelopes. Cell envelopes were obtained by differential centrifugation after ultrasonic disruption of the cells and analyzed by sodium dodecyl sulfate-polyacrylamide gel electrophoresis (11).

Antiserum preparation and immunoblot analysis. The 90,000 - and 92,000-dalton outer membrane proteins of WCS358 were excised from a sodium dodecyl sulfate-polyacrylamide gel and isolated by electroelution. A rabbit was immunized by three successive injections with 60 to $100 \mu \mathrm{g}$ of a mixture of these two proteins. Immunoblot procedures have been described previously (12), except that for optimal separation of the 90,000 - and 92,000 -dalton proteins a $9 \%$ polyacrylamide gel was used and electrophoresis was extended for $1 \mathrm{~h}$ after the disappearance of the bromophenol blue color front from the gel.

Protein synthesis in $E$. coli minicells. Minicells were isolated and labeled with $\left[{ }^{35} \mathrm{~S}\right]$ methionine $(10 \mu \mathrm{Ci})$ essentially as described by Andreoli et al. (1). Radiolabeled proteins were analyzed by autoradiography after electrophoresis on sodium dodecyl sulfate-polyacrylamide gels (19).

\section{RESULTS}

Siderophore specificity of two different Pseudomonas strains. The specificity in the utilization of the siderophores produced by strains WCS358 and WCS374 was investigated by incubation of both strains on $\mathrm{KB}$ agar plates that contained various concentrations of purified siderophore pseudobactin 358 or pseudobactin 374 .

The siderophore produced by WCS358 inhibited the growth of wild-type WCS374 at concentrations of $50 \mu \mathrm{M}$ and higher, while the growth of WCS358 was not affected at all (Table 1). The WCS374 siderophore caused no growth inhibition of either strain at any of the concentrations used. The growth inhibition of WCS374 by pseudobactin 358 was caused by iron deprivation, as it could be overcome by the addition of $\mathrm{Fe}^{3+}$ (data not shown). This result indicates that ferric pseudobactin 358 cannot be utilized by WCS374.

This result has also been demonstrated in ${ }^{55} \mathrm{Fe}^{3+}$ uptake experiments with both siderophores (10). WCS358 cells grown under iron-limited conditions were able to take up $\mathrm{Fe}^{3+}$ from their own $\mathrm{Fe}^{3+}$-siderophore complex as well as from the $\mathrm{Fe}^{3+}$-pseudobactin 374 complex. WCS374 cells grown under iron-limited conditions were only able to incorporate $\mathrm{Fe}^{3+}$ from the $\mathrm{Fe}^{3+}$-pseudobactin 374 complex. WCS358 and WCS374 were equally efficient in utilizing the iron from the $\mathrm{Fe}^{3+}$-pseudobactin 374 complex, whereas WCS358 was about four times more efficient than was WCS374 when it used its own siderophore. 


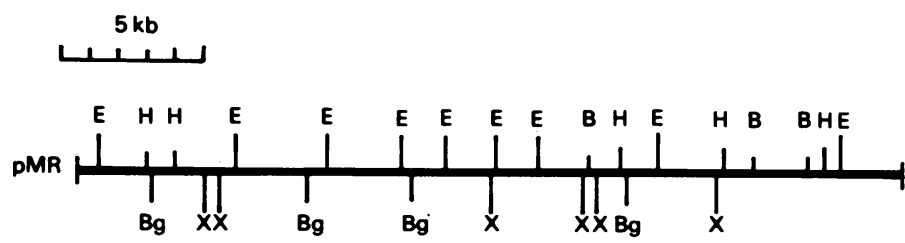

Pseudobactin 358 competence:
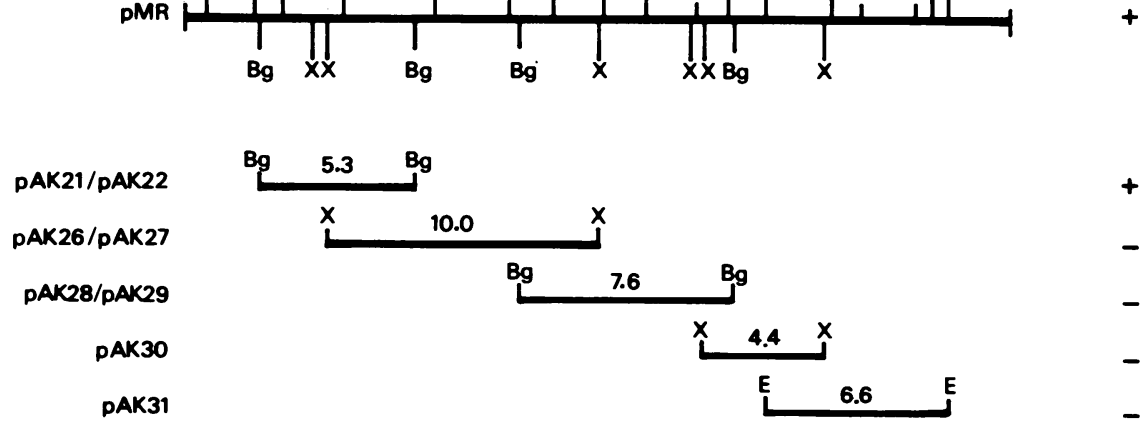

7.6

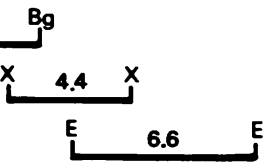

FIG. 1. Physical map of cosmid pMR and subclones constructed in this study. The horizontal lines represent the various insert DNAs cloned in the broad-host-range cosmid pLAFR1B (pMR) or in the broad-host-range vector pKT240 (pAK21 to pAK31). Numbers denote fragment sizes in kilobases. E, EcoRI; H, HindIII; B, Bam HI; Bg, BglII; X, Xhol. Pseudobactin 358 competence is defined as the ability of the specified plasmids to allow WCS374 transconjugants to utilize pseudobactin 358 (see text for details).

Introduction into WCS374 of the competence to utilize pseudobactin 358. The inability of WCS374 to take up iron via pseudobactin 358 was used to identify genes and proteins of WCS358 that are involved in this uptake process, e.g., outer membrane receptor proteins. For this purpose a gene bank of strain WCS358 was transferred to strain WCS374, and transconjugant WCS374 cells were tested to determine whether they had become competent to utilize pseudobactin 358.

A WCS358 gene bank was constructed by cloning partial Sau3A DNA fragments from the WCS358 genome into the mobilizable cosmid pLAFR1B, a pLAFR1 derivative (15) containing a unique (Sau3A-compatible) BamHI site (see Materials and Methods). The resulting gene bank consisted of 2,000 independent clones with insert lengths that varied from 20 to $30 \mathrm{~kb}$, sufficient to represent any DNA sequence of the genome with a probability of $99 \%$ (6). The gene bank was conjugated into WCS374 with the helper plasmid pRK2013 (14). To facilitate screening we used the nonfluorescing strain $\mathrm{KM} 26$, a siderophore-defective ( $\mathrm{Sid}^{-}$) derivative of WCS374, since it was not able to grow at low $(25 \mu \mathrm{M})$ pseudobactin 358 concentrations. Transconjugants were selected by plating on $\mathrm{KB}$ agar containing nalidixic acid and tetracycline. We then replica plated nalidixic acid- and tetracycline-resistant transconjugants to $\mathrm{KB}$ agar plates supplemented with both antibiotics and to plates that also contained pseudobactin 358 . In this way we identified a single cosmid clone that rescued KM26 from iron starvation induced by pseudobactin 358. Cosmid DNA was isolated from the transconjugant colony, transfected to $E$. coli $\mathrm{HB} 101$, and mobilized into KM26 to verify that the presence of the cosmid DNA was conditional for the ability to grow on pseudobactin 358. The transconjugant cells were able to grow in the presence of pseudobactin 358.

A restriction map of the insert DNA $(29.4 \mathrm{~kb})$ of cosmid pMR was constructed for the enzymes EcoRI, BamHI, XhoI, HindIII, and BglII (Fig. 1). Southern analysis in which radiolabeled pMR was hybridized with EcoRI and HindIII digests of genomic DNA from wild-type WCS358 demonstrated that the pMR insert was in fact a hybrid DNA molecule composed of two normally unlinked DNA fragments: e.g., a 6.6-kb EcoRI fragment present in pMR (Fig. 1) was not seen on the blot, but instead two fragments of 5.7 and $7.8 \mathrm{~kb}$ were observed (Fig. 2). Similarly, on the blot of the HindIII digest the 3.8-kb fragment positioned within the 6.6-kb EcoRI fragment was replaced by two new fragments (data not shown). This result indicates that an illegal ligation event had occurred prior to the ligation of the insert with the vector DNA. Part of the 6.6-kb EcoRI fragment plus the complete 2.1-kb EcoRI fragment of pMR (the right part, Fig. 1) originated from a different part of the WCS358 genome than the remaining DNA (approximately $24 \mathrm{~kb}$ ).

Subcloning and Tn5 mutagenesis. The location on the pMR insert DNA of the gene(s) responsible for the utilization of pseudobactin 358 by WCS374 [pseudobactin 358 uptake gene(s)] was analyzed by Tn5 mutagenesis and by subcloning of the large insert. BglII, XhoI, and EcoRI fragments of

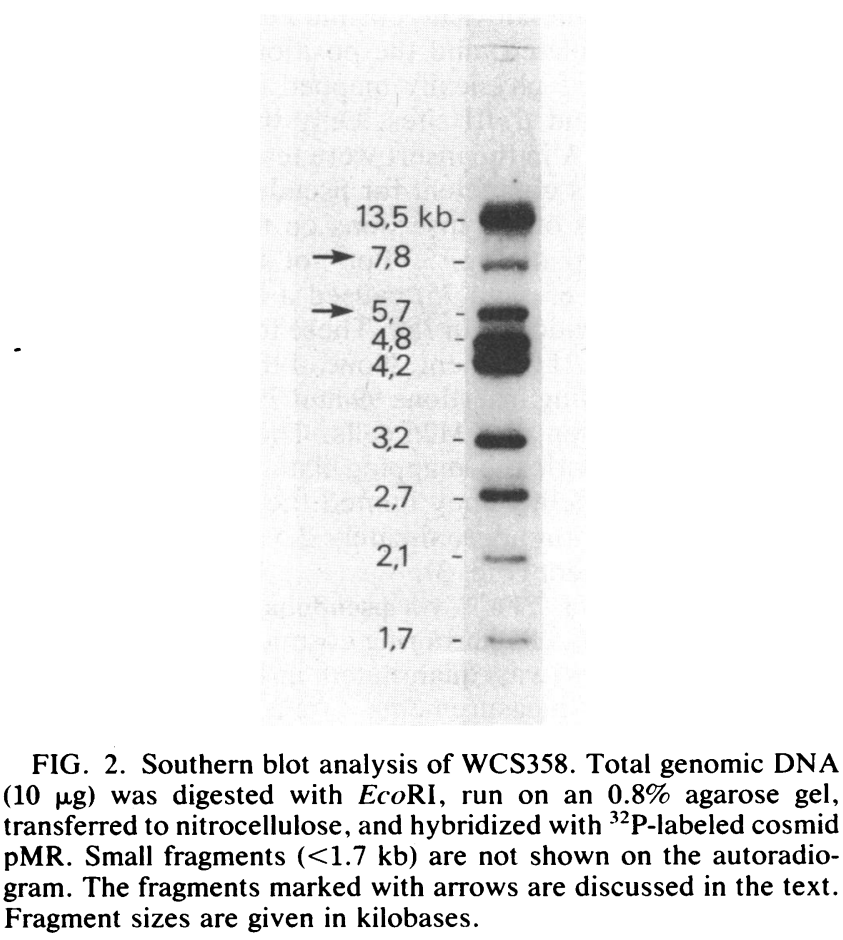




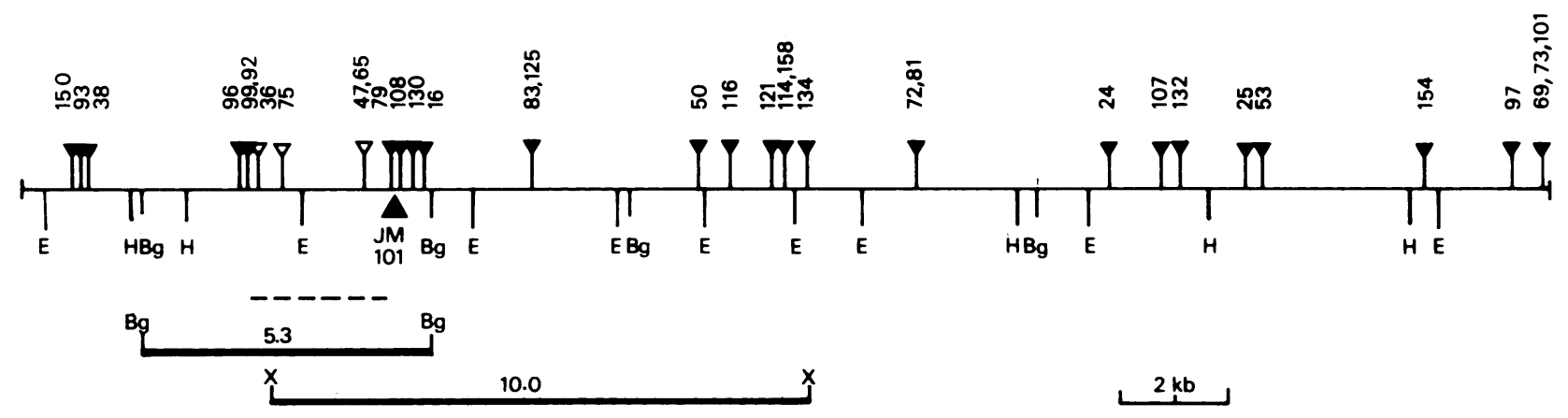

FIG. 3. Locations of $\mathrm{Tn} 5$ insertions on the insert of cosmid pMR. Open triangles refer to $\mathrm{Tn} 5$ insertions that caused a loss of the ability to make WCS374 cells competent for pseudobactin 358 utilization, and closed triangles refer to $\mathrm{Tn} 5$ insertions that did not affect pseudobactin 358 utilization by WCS374 cells. The broken line limits the DNA region required for the utilization of pseudobactin 358 . The positions of the 5.3-kb BgllI and 10.0-kb XhoI fragments are indicated by the heavy lines. The location of the genomic Tn5 insertion of the siderophoredefective mutant JM101 is indicated by the large triangle. Restriction enzyme abbreviations are explained in the legend to Fig. 1.

cosmid pMR were cloned in the mobilizable broad-hostrange vector pKT240 (2) at the unique $B a m H I, X h o I$, and EcoRI sites, respectively. The cloned fragments and their positions within pMR are given in Fig. 1. Each of these subclones was mobilized to KM26 and screened for competence for pseudobactin 358 utilization. Only plasmids containing a 5.3-kb BglII fragment in different orientations (pAK21 and pAK22) were able to make WCS374 competent to utilize pseudobactin 358 (Fig. 1). The 10.0-kb XhoI fragment overlaps most of the 5.3-kb BglII fragment, but it did not make WCS374 competent to utilize pseudobactin 358. Therefore, the essential DNA is present in the left part of the $B g$ lII fragment or overlaps the left border of the XhoI fragment (Fig. 1).

Cosmid pMR was mutagenized by infection of $E$. coli HB101(pMR) with bacteriophage lambda::Tn5 (27). The mutagenized cosmids were isolated and used for transformation of HB101. After selection for kanamycin and tetracycline resistance, transformants were pooled and conjugated en masse with KM26. After selection on KB agar with tetracycline and nalidixic acid, cosmid DNA from 200 transconjugants was isolated, and the positions of each of their Tn 5 insertions were physically mapped relative to flanking EcoRI, HindIII, and BglII sites. Only the 34 pMR derivatives with Tn5 DNA in the insert were tested for their ability to make their hosts competent for pseudobactin 358 utilization. The positions of the insertions on the pMR insert are shown on the map in Fig. 3. Four of the Tn5 insertions (insertions 36, 47, 65, and 75) caused a loss of the competence to utilize pseudobactin 358 . These four insertions were all in the $5.3-\mathrm{kb} B g l \mathrm{II}$ fragment. None of the other insertions, including surrounding insertions 99 and 79, affected pseudobactin 358 utilization of KM26 cells. These results were in good agreement with the mapping data obtained with the subclones, and together they limited the essential information to a DNA region approximately $2.5 \mathrm{~kb}$ long within the 5.3-kb BglII fragment (Fig. 3).

Specific uptake of ${ }^{55} \mathrm{Fe}^{3+}$ via pseudobactin 358. The iron uptake of WCS374 cells harboring cosmid pMR or its mutagenized derivatives was quantitated in pseudobactin 358mediated uptake measurements. ${ }^{55} \mathrm{Fe}^{3+}$ complexed to pseudobactin 358 and supplied to WCS374(pMR) cells grown under $\mathrm{Fe}^{3+}$ limitation was taken up efficiently (Fig. 4). WCS374 cells without the cosmid did not take up $\mathrm{Fe}^{3+}$ from the ${ }^{55} \mathrm{Fe}^{3+}$-pseudobactin 358 complex (Fig. 4). WCS374 cells harboring mutagenized pMR derivatives (derivatives 36, 47, 65 , and 75) were also not able to take up $\mathrm{Fe}^{3+}$ from the complex, as shown for pMR-36 in Fig. 4. WCS374 cells carrying pAK22 (Fig. 4) or pAK21 (data not shown) were as efficient in the uptake of $\mathrm{Fe}^{3+}$ from ferric pseudobactin 358 as were WCS374(pMR) cells. These results clearly confirmed the previous data.

Identification of the gene product. The expression of clone pAK21 was analyzed in E. coli minicells. A protein with an MW of about 85,000 was only produced in minicells that carried this plasmid (Fig. 5, lane 2). Recently (22), we showed that both orientations of this 5.3-kb BglII fragment expressed the $85,000-\mathrm{MW}$ protein, suggesting the presence of a promoter on the fragment.

When strain WCS358 is grown under iron limitation the expression of a number of proteins, including two outer membrane proteins with MWs of 90,000 and 92,000 , is induced $(11,31)$. An antiserum raised against a mixture of these two proteins was used to analyze the synthesis of both proteins in WCS358 and to test whether WCS374 harboring pMR produced any of these proteins. Figure 6 (lanes 2 and 9) and Fig. 7 (lane 1) show that indeed only the 90,000- and 92,000-MW proteins of cell envelopes isolated from iron(III)limited WCS358 cells reacted in immunoblots with this antiserum. Cell envelopes of cells grown with excess $\mathrm{Fe}^{3+}$

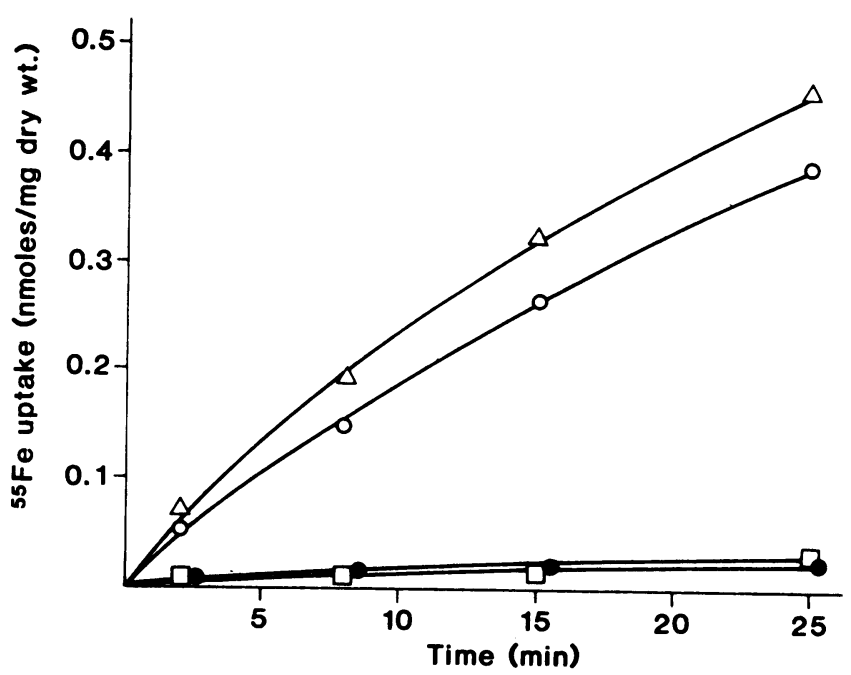

FIG. 4. Pseudobactin 358-mediated ${ }^{55} \mathrm{Fe}$ uptake by cells of WCS374 (O), WCS374(pMR) (○), WCS374(pAK22) $(\triangle)$, and WCS374(pMR-36) ( $\square$ ) grown under iron limitation. 


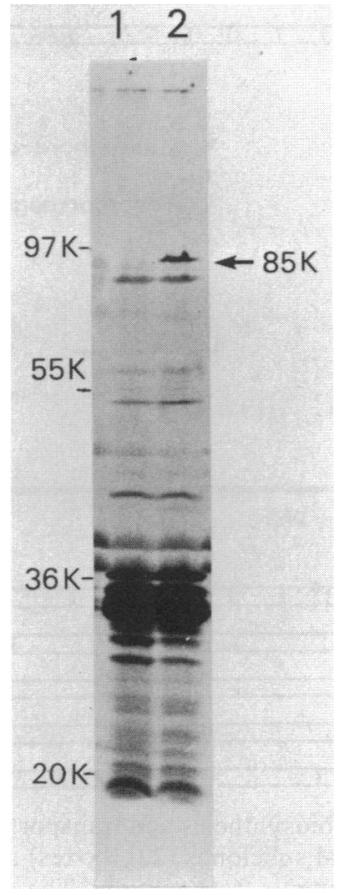

FIG. 5. Sodium dodecyl sulfate-polyacrylamide gel electrophoresis of ${ }^{35} \mathrm{~S}$-labeled polypeptide products in minicells containing pKT240 (lane 1) or pAK21 (lane 2). MW marker proteins (in thousands [K]) were phosphorylase $b(97 \mathrm{~K})$, glutamate dehydrogenase $(55 \mathrm{~K})$, lactate dehydrogenase $(36 \mathrm{~K})$, and trypsin inhibitor (20K).

showed no reaction (Fig. 7, lane 2). The antiserum crossreacted with a $91,000-\mathrm{MW}$ protein present in cell envelopes isolated from iron(III)-limited WCS374 cells (Fig. 6, lane 1, and Fig. 7, lane 3). Here also cell envelopes prepared from cells grown under iron-rich conditions did not react (Fig. 7, lane 4).

Cell envelopes of different WCS374 cells containing cosmid pMR or its derivatives were analyzed on immunoblots with this antiserum. Only in cell envelopes of WCS374 cells that harbored cosmid pMR and that were grown under iron(III) limitation was a new protein (besides the endogenous $91,000-\mathrm{MW}$ protein) which comigrated with the

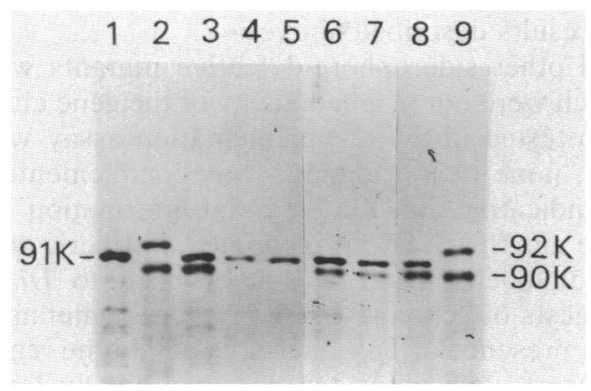

FIG. 6. Immunoblot analysis of cell envelope preparations run on a $9 \%$ sodium dodecyl sulfate-polyacrylamide gel with an antiserum raised against a mixture of $90,000(90 \mathrm{~K})$ - and $92,000(92 \mathrm{~K})-\mathrm{MW}$ proteins of WCS358. Cell envelopes were isolated from cells grown under iron limitation. Lanes: 1, WCS374; 2 and 9, WCS358; 3, WCS374(pMR); 4, WCS374(pMR-36); 5, WCS374(pMR-47); 6, WCS374(pAK21); 7, WCS374(pAK22); 8, WCS374(pMA3).

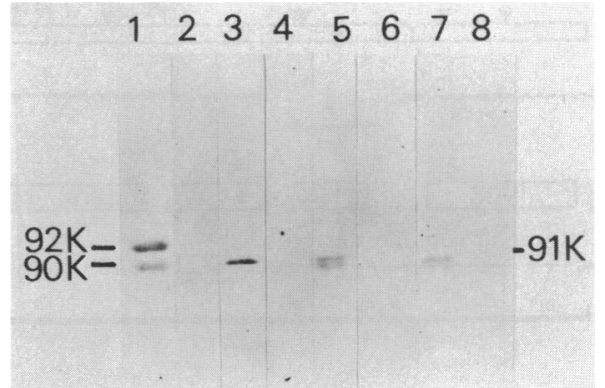

FIG. 7. Immunoblot analysis of cell envelope preparations run on an $11 \%$ sodium dodecyl sulfate-polyacrylamide gel with the antiserum raised against the 90,000 - and $92,000-\mathrm{MW}$ proteins (see the legend to Fig. 6). Cell envelopes were prepared from WCS358 and WCS374 cells grown under iron-limited (lanes 1, 3, 5, and 7) or iron-rich (lanes 2, 4, 6, and 8) conditions. Lanes: 1 and 2, WCS358; 3 and 4, WCS374; 5 and 6, WCS374(pMR); 7 and 8, WCS374 (pAK22).

WCS358 90,000-MW protein expressed (Fig. 6, lane 3, and Fig. 7, lane 5). Under iron-rich conditions the 90,000-MW protein (and the $91,000-\mathrm{MW}$ protein) was not observed (Fig. 7 , lane 6), indicating that the mechanism of iron regulation in both strains is very much alike or even identical. In cell envelopes of WCS374 cells harboring the mutagenized pMR derivatives 36 and 47 , the $90,000-\mathrm{MW}$ protein had disappeared (Fig. 6, lanes 4 and 5). Together with the fact that these cells were not able anymore to take up $\mathrm{Fe}^{3+}$ via pseudobactin 358 , this result demonstrated that the 90,000 MW protein was responsible for pseudobactin 358-specific iron uptake. Cell envelopes of only iron-limited WCS374 cells harboring plasmid pAK21 or pAK22, containing the 5.3-kb $B g$ /II fragment of pMR, also contained the $90,000-$ MW protein (Fig. 6, lanes 6 and 7, and Fig. 7, lane 7). This result strongly suggests that this protein is identical to the $85,000-\mathrm{MW}$ protein observed in the minicell analysis. The observed difference in size is very likely the result of differences in the resolution of the gel systems used. Cell envelopes of normal (not minicell-producing) $E$. coli cells containing cosmid pMR or either subclone did not react with the antiserum, probably as a result of poor expression of the gene or instability of the gene product in $E$. coli.

Linkage to siderophore biosynthesis genes. The restriction digestion pattern of the left end of the pMR insert (comprising the 4.8- and 3.2-kb EcoRI fragments; Fig. 1) looks very similar to a region of the previously characterized gene cluster $\mathrm{A}$, which was shown to be involved in the biosynthesis of pseudobactin 358 (22). To check whether this similarity indeed indicates that $\mathrm{pMR}$ and cluster $\mathrm{A}$ are linked, we hybridized radiolabeled DNA of cosmid pMA3 of cluster A (22) with an EcoRI digest of pMR on a Southern blot. Strong hybridization occurred with the EcoRI fragments of $0.8,3.2$, and $4.8 \mathrm{~kb}$ (data not shown), demonstrating that cosmids pMR and pMA3 had an overlap of about 8.8 $\mathrm{kb}$, i.e., the 4.8- and 3.2-kb EcoRI fragments plus $0.8 \mathrm{~kb}$ of the 13.5-kb EcoRI fragment, as present on cosmid pMA3. Since the information for pseudobactin 358 utilization is situated within the 5.3-kb $B g / I I$ fragment present on the overlapping areas of cosmids pMR and pMA3 (Fig. 8), the latter cosmid was tested to see whether it also could make WCS374 cells competent for the utilization of pseudobactin 358 . WCS374 cells harboring pMA3 produced the 90,000 MW protein (Fig. 6, lane 8) and were able to efficiently take up $\mathrm{Fe}^{3+}$ from pseudobactin 358 (data not shown). Subclones 


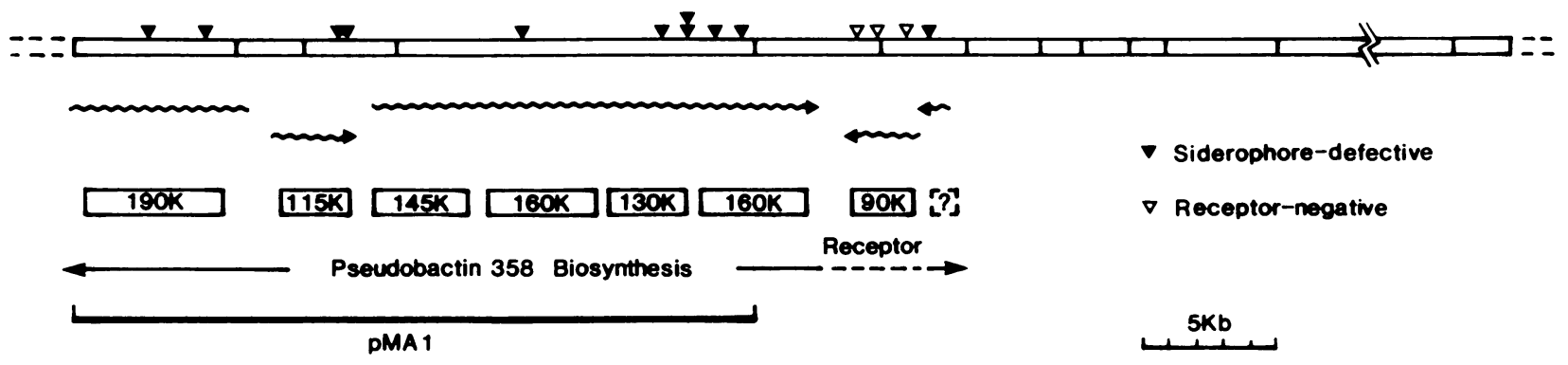

PMA3

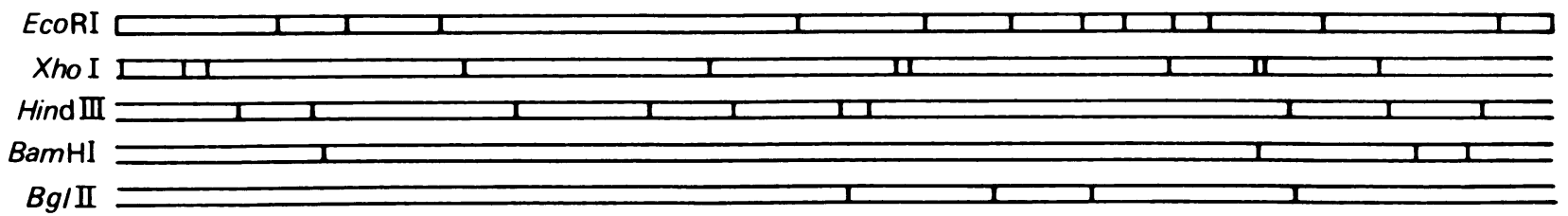

FIG. 8. Genetic organization of $P$. putida WCS358 gene cluster A involved in siderophore biosynthesis and transport. The orientation and direction of transcriptional units (wavy arrows) and polypeptide products encoded by several subclones (22) (boxes) are shown. Open and closed triangles refer to the $\mathrm{Tn} 5$ insertions of siderophore-defective and receptor-negative mutants, respectively. The restriction map at the bottom was combined from the data for the overlapping cosmid clones pMA1 (23), pMA3 (23), and pMR (heavy lines). K, Thousands.

pAK21 and pAK22 (containing the 5.3-kb BgllI fragment) were in fact derived from cosmid pMA3 of cluster A (22).

The linkage of the cosmids was also demonstrated by a complementation analysis of the nonfluorescent mutant JM101 (23) which Tn5 insertion was shown to disturb a transcriptional unit located in the 3.2-kb EcoRI fragment (22; Fig. 3 and 8). Cosmid pMA3 was able to complement the mutation in JM101. After mobilization to JM101, cosmid pMR also complemented the defect in the mutant, as measured by the restoration of fluorescence (23).

The transcriptional organization of this biosynthesis gene, which is disturbed in JM101, and the pseudobactin 358 uptake gene was analyzed by mobilizing mutagenized pMR derivatives to JM101 and subsequently screening transconjugants for the restoration of fluorescence. pMR derivatives carrying insertions $16,79,108$, and 130 (Fig. 3) did not complement the mutation in JM101, whereas all other insertions, including, e.g., 47, 36, and 75, did not affect complementation, and fluorescence was restored completely. This result shows very clearly that the biosynthesis gene and the pseudobactin 358 uptake gene are on separate transcriptional units.

\section{DISCUSSION}

We have identified a gene from $P$. putida WCS358 that provides $P$. fluorescens WCS374 with competence for the utilization of the siderophore pseudobactin 358 . The gene encodes an iron-regulated outer membrane protein that has an apparent MW of 90,000 and that probably functions as the receptor for ferric pseudobactin 358. The gene has been localized on a $5.3-\mathrm{kb} B g / \mathrm{lI}$ fragment by subcloning and is limited by $\mathrm{Tn} 5$ mutagenesis to a region of about $2.5 \mathrm{~kb}$ within this fragment. This length of DNA would be sufficient to encode a gene product with an MW of 90,000 .

The WCS358 cosmid clone pMR, which contains this gene, was found to be linked to the recently characterized gene cluster $\mathrm{A}$, involved in the biosynthesis of pseudobactin (22). This region has now been extended to approximately 50 kb (Fig. 8). The receptor gene is flanked on both sides by biosynthesis genes, as shown by the positions of the Tn5 insertions of several mutants that are defective in the biosynthesis of the siderophore (e.g., JM101 and JM211) (22). The receptor gene and the biosynthesis genes are on separate transcriptional units. This fact was demonstrated in a complementation assay with pMR derivatives which carried $\mathrm{Tn} 5$ insertions in each of the genes: pMR derivatives with mutations in the receptor gene were still able to complement the biosynthesis mutant JM101, whereas pMR derivatives which did not complement JM101 still could make strain WCS374 competent for pseudobactin 358 utilization. These results are in agreement with those of our previous investigation which demonstrated the presence of two transcriptional units within the 5.3-kb BglII fragment (22). One of the transcripts was detected on a Northern (RNA) blot and measured about 2.4 to $2.8 \mathrm{~kb}$, a length which fits quite well with the results described above.

Several other siderophore-defective mutants with mutations which were not mapped in any of the gene clusters (23) were also tested in the complementation assay with pMR. However, none of the mutants was complemented by the cosmid, indicating that the essential information is located elsewhere on the WCS358 genome. Southern analysis in which radiolabeled pMR was hybridized to HindIII and EcoRI digests of genomic DNA from these mutants did not reveal the presence of $\operatorname{Tn} 5$ insertions within the region of the cosmid insert, confirming the previous conclusion (unpublished results).

The $90,000-\mathrm{MW}$ protein is expressed only when WCS358 cells are grown under iron limitation. This iron-dependent expression of the gene is regulated at the transcriptional level; in the presence of iron no transcript is found (22). In WCS374 cells the pMR gene is expressed at the same level as 
in WCS358 cells and is also regulated by iron, suggesting that the regulatory signals and proteins in both strains must be quite homologous or even identical.

The presence of a single WCS358 protein in the cell envelopes of WCS374 is sufficient to make this strain competent for the utilization of ferric pseudobactin 358 . It is likely, however, that other proteins are also involved in the iron uptake process in Pseudomonas strains. In $E$. coli all siderophore systems, including, e.g., enterobactin and aerobactin, require the participation of several inner membraneassociated proteins in addition to the specific receptors (3). Our results indicate that these not-yet-identified proteins are less specific or even very similar in WCS374 and WCS358 and are capable of interacting with both the WCS374 and WCS358 receptor proteins. The specificity of the uptake process therefore seems mainly to depend on the recognition of the iron-siderophore complex by the $90,000-\mathrm{MW}$ outer membrane receptor protein.

Recently, a gene encoding an 85,000 -MW outer membrane protein involved in the uptake of ferric pseudobactin in Pseudomonas sp. strain B10 was identified (20). By sitespecific exchange mutagenesis the investigators had created mutants which did not produce the $85,000-\mathrm{MW}$ protein anymore and which were unable to take up ferric pseudobactin. In this study our investigations were focused on the heterologous utilization of pseudobactin 358. In WCS374 cells carrying the defective gene for the $90,000-\mathrm{MW}$ protein, $\mathrm{Fe}^{3+}$ was not taken up from $\mathrm{Fe}^{3+}$-pseudobactin 358. In a forthcoming paper (W. Bitter, J. D. Marugg, L. A. de Weger, J. Tommassen, and P. J. Weisbeek, manuscript in preparation) it will be reported that WCS358 cells defective in the synthesis of the $90,000-\mathrm{MW}$ protein are still able to take up $\mathrm{Fe}^{3+}$ delivered by pseudobactin 358 , although with greatly decreased efficiency. This result seems to be in contrast with that for the $\mathrm{B} 10$ receptor mutants (20) and is an indication that WCS358 contains an alternative receptor protein which also can recognize ferric pseudobactin 358 . The same mutants are also still able to utilize pseudobactin 374 , just like the wild type, again indicating the presence of an alternative receptor protein.

The utilization of a heterologous siderophore by WCS358 is not limited to pseudobactin 374: it has been shown that WCS358 is able to utilize many other siderophores produced by a great number of Pseudomonas soil isolates (P. Bakker, unpublished results). Some of these siderophores have been partly characterized and shown to be different from pseudobactin 358. An intriguing question is whether the uptake of these other siderophores by WCS358 occurs via a single receptor protein with a low specificity or via a number of more specific receptors.

Strain WCS358 seems to be special in its ability to acquire iron from its environment. More research is necessary to identify the pathways involved and the consequences of this broad-host-range siderophore utilization, factors which are likely to be of prime importance in its role as a plantgrowth-promoting rhizosphere Pseudomonas strain.

\section{ACKNOWLEDGMENTS}

We thank Peter van der Meide for his support in the antiserum preparation.

This investigation was supported in part by The Netherlands Technology Foundation and by E.E.C. grant GBI-4-108 NL from the Biomolecular Engineering Programme.

\section{LITERATURE CITED}

1. Andreoli, P. M., N. Overbeeke, E. Veltkamp, J. D. A. van Embden, and H. J. J. Nijkamp. 1978. Genetic map of the bacteriocinogenic plasmid CloDF13 derived by insertion of the transposon Tn901. Mol. Gen. Genet. 160:1-11.

2. Bagdasarian, M. M., E. Amann, R. Lurz, B. Rückert, and $M$. Bagdasarian. 1983. Activity of the hybrid trp-lac (tac) promoter of Escherichia coli in Pseudomonas putida. Construction of broad-host-range, controlled-expression vectors. Gene 26:273282.

3. Bagg, A., and J. B. Neilands. 1987. Molecular mechanism of regulation of siderophore-mediated iron assimilation. Microbiol. Rev. 51:509-518.

4. Berg, D. E., J. Davies, B. Allet, and J.-D. Rochaix. 1975. Transposition of $\mathbf{R}$ factor genes to bacteriophage lambda. Proc. Natl. Acad. Sci. USA 72:3628-3632.

5. Buyer, J. S., and J. Leong. 1986. Iron transport-mediated antagonism between plant growth-promoting and plant-deleterious Pseudomonas strains. J. Biol. Chem. 261:791-794.

6. Clarke, L., and J. Carbon. 1976. A colony bank containing synthetic ColE1 hybrid plasmids representative of the entire $E$. coli genome. Cell 9:91-99.

7. Cody, Y. S., and D. C. Gross. 1987. Characterization of pyover$\operatorname{din}_{\mathrm{pss}}$, the fluorescent siderophore produced by Pseudomonas syringae pv. syringae. Appl. Environ. Microbiol. 53:928-934.

8. Cody, Y. S., and D. C. Gross. 1987. Outer membrane protein mediating iron uptake via pyoverdin ${ }_{\mathrm{pss}}$, the fluorescent siderophore produced by Pseudomonas syringae pv. syringae. J. Bacteriol. 169:2207-2214.

9. Demange, P., S. Wendenbaum, A. Bateman, A. Dell, J. M. Meyer, and M. A. Abdallah. 1986. Bacterial siderophores: structure of pyoverdins and related compounds. NATO ASI Ser. Ser. A 117:131-147.

10. de Weger, L. A., J. J. C. M. van Arendonk, K. Recourt, G. A. J. M. van der Hofstad, P. J. Weisbeek, and B. Lugtenberg. 1988. Siderophore-mediated uptake of $\mathrm{Fe}^{3+}$ by the plant growthstimulating Pseudomonas putida strain WCS358 and by other rhizosphere microorganisms. J. Bacteriol. 170:4693-4698.

11. de Weger, L. A., R. van Boxtel, B. van der Burg, R. Gruters, F. P. Geels, B. Schippers, and B. Lugtenberg. 1986. Siderophores and outer membrane proteins of antagonistic plantgrowth-stimulating, root-colonizing Pseudomonas spp. J. Bacteriol. 165:585-594.

12. de Weger, L. A., C. I. M. van der Vlugt, A. H. M. Wijfjes, P. A. H. M. Bakker, B. Schippers, and B. Lugtenberg. 1987. Flagella of a plant-growth-stimulating Pseudomonas fluorescens strain are required for colonization of potato roots. J. Bacteriol. 169:2769-2773.

13. Ditta, G., S. Stanfield, D. Corbin, and D. R. Helinski. 1980. Broad host range DNA cloning system for gram-negative bacteria: construction of a gene bank of Rhizobium meliloti. Proc. Natl. Acad. Sci. USA 77:7347-7351.

14. Figurski, D. H., and D. R. Helinski. 1979. Replication of an origin-containing derivative of plasmid RK2 dependent on a plasmid function provided in trans. Proc. Natl. Acad. Sci. USA 76:1648-1652.

15. Friedman, A. M., S. R. Long, S. E. Brown, W. J. Buikema, and F. M. Ausubel. 1982. Construction of a broad host range cosmid cloning vector and its use in the genetic analysis of Rhizobium mutants. Gene 18:289-296.

16. Geels, F. P., and B. Schippers. 1983. Reduction of yield depressions in high frequency potato cropping soil after seed tuber treatments with antagonistic fluorescent Pseudomonas spp. Phytopathol. Z. 108:207-214.

17. Grosveld, F. G., H. M. Dahl, E. der Boer, and R. A. Flavell. 1981. Isolation of $\beta$-globin-related genes from a human cosmid library. Gene 13:227-237.

18. Hohnadel, D., and J. M. Meyer. 1986. Pyoverdine-facilitated iron uptake among fluorescent pseudomonads. NATO ASI Ser. Ser. A 117:119-129.

19. Lugtenberg, B., J. M. Meijers, R. Peters, P. van der Hoek, and L. van Alphen. 1975. Electrophoric resolution of the 'major outer membrane protein' of Escherichia coli K12 into four bands. FEBS Lett. 58:254-258.

20. Magazin, M. D., J. C. Moores, and J. Leong. 1986. Cloning of the gene coding for the outer membrane receptor protein for 
ferric pseudobactin, a siderophore from a plant growth-promoting Pseudomonas strain. J. Biol. Chem. 261:795-799.

21. Maniatis, T., E. F. Fritsch, and J. Sambrook. 1982. Molecular cloning: a laboratory manual. Cold Spring Harbor Laboratory, Cold Spring Harbor, N.Y.

22. Marugg, J. D., H. B. Nielander, A. J. G. Horrevoets, I. van Megen, I. van Genderen, and P. J. Weisbeek. 1988. Genetic organization and transcriptional analysis of a major gene cluster involved in siderophore biosynthesis in Pseudomonas putida WCS358. J. Bacteriol. 170:1812-1819.

23. Marugg, J. D., M. van Spanje, W. P. M. Hoekstra, B. Schippers, and P. J. Weisbeek. 1985. Isolation and analysis of genes involved in siderophore biosynthesis in plant-growing-stimulating Pseudomonas putida WCS358. J. Bacteriol. 164:563-570.

24. Meyer, J. M., M. Mock, and M. A. Abdallah. 1979. Effect of iron on the protein composition of the outer membrane of fluorescent pseudomonads. FEMS Microbiol. Lett. 5:395-398.

25. Neilands, J. B. 1981. Microbial iron compounds. Annu. Rev. Biochem. 50:715-731.

26. Neilands, J. B. 1982. Microbial envelope proteins related to iron.
Annu. Rev. Microbiol. 36:285-309.

27. Shaw, K. J., and C. M. Berg. 1979. Escherichia coli K-12 auxotrophs induced by insertion of the transposable element Tn5. Genetics 92:741-747.

28. Teintze, M., M. B. Hossain, C. L. Barnes, J. Leong, and D. van der Helm. 1981. Structure of ferric pseudobactin, a siderophore from a plant growth promoting Pseudomonas. Biochemistry 20:6446-6457.

29. van der Hofstad, G. A. J. M., J. D. Marugg, G. M. G. M. Verjans, and P. J. Weisbeek. 1986. Characterization and structural analysis of the siderophore produced by the PGPR Pseudomonas putida strain WCS358. NATO ASI Ser. Ser. A 117: 71-75.

30. Vieira, J., and J. Messing. 1982. The pUC plasmids, an M13mp7-derived system for insertion mutagenesis and sequencing with synthetic universal primers. Gene 19:259-268.

31. Weisbeek, P. J., G. A. J. M. van der Hofstad, B. Schippers, and J. D. Marugg. 1986. Genetic analysis of the iron-uptake system of two plant growth-promoting Pseudomonas strains. NATO ASI Ser. Ser. A 117:299-313. 